\title{
PRACTICEOPOLIS From an Imaginary City to a Graphic Novel
}

\author{
Adam Sharr, \\ School of Architecture, Planning and Landscape, \\ Newcastle University \\ adam.sharr@ncl.ac.uk \\ (+44) 1912087832 \\ Yasser Megahed, \\ School of Architecture, Planning and Landscape, \\ Newcastle University \\ Yasser.megahed@ncl.ac.uk \\ (+44) 7403108408
}

\section{ABSTRACT}

This essay is about a graphic novel produced as the culmination of a creative practice research project. It dramatizes real-life exchanges from project management meetings held during the conduct a live architectural project in the UK, re-siting those exchanges to an imaginary city as high-stakes public debates. The graphic novel depicts these exchanges as value-conflicts in order to examine the ideologies at work among architects and other actors in the construction industry. The research represents a special creative space that challenges design research practices in order to create new strategies and methods for design as scholarship. 



\section{PRACTICEOPOLIS \\ From an Imaginary City to a Graphic Novel}



Fig. 1: Practiceopolis - the City-state within Constructopolis, the confederation of the building industry (the Authors)
The genre of the graphic novel is rarely tested as a research method. This essay is about a graphic novel produced as the culmination of a creative practice research project. It was made as a dramatization of real-life exchanges from project management meetings held during the conduct of a live architectural project in the UK, re-siting those exchanges to an imaginary city as high-stakes public debates. The graphic novel form allowed the exchanges to be depicted as value-conflicts in order to examine the ideologies at work among architects and other actors in the construction industry. The project emerged from a research-led architecture office, based in a university, where live projects are employed as springboards for design research, not treating projects directly as research but instead by taking thematic cuts through the practice work to draw-out significant research themes. This research project followed a series of stages, reflecting upon - and critiquing - the values of the contemporary architectural profession. Using the live project as a case study, it focused on the competition for economic and cultural capital between different cultures of practice operating within the architectural profession in the UK, in the light of the domination of technical-rational ${ }^{1}$ values in the culture of the contemporary British building industry. The outcome of this research project was an architectural graphic novel set in an imaginary metropolis representing the contemporary architectural profession, named Practiceopolis, centered on the fictive island of the Confederation of the Building Industry (Figure 1).

The first stages of the research involved diagramming prevailing values in the architectural profession and the construction industry more broadly, identifying the most prominent cultures of practice. This 
exercise drew from the philosopher Andrew Feenberg's classification of varying stances towards technology and technical knowledge, interpreting them as ideological positions that reflect the values of the different cultures of practice defining the contemporary architectural profession. ${ }^{2}$ The initial diagram becomes a map which becomes the plan for the speculative city. The city became envisaged through a sequence of iterative narratives where each narration set the foundation for the next, posing specific questions about the values operating within the architectural profession.
Fig. 2 (below), Excerpts from the graphic novel "Stories from Practiceopolis" (the Authors)

\section{THE GRAPHIC NOVEL}
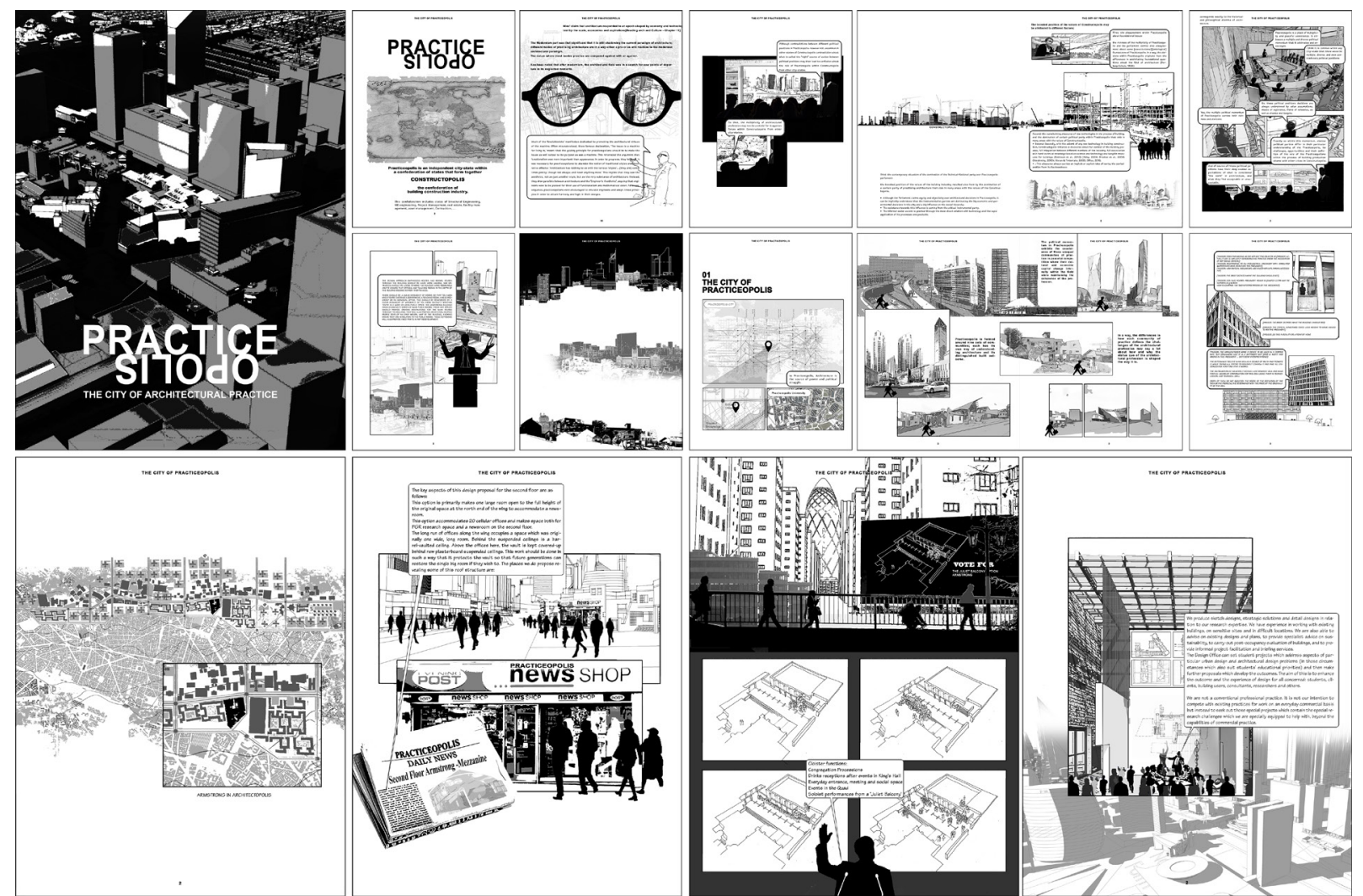

The most substantial - and somewhat unexpected - outcome of the research is the production of an architecturally-themed graphic novel, situated in the imaginary realm of Practiceopolis. It followed our office's appointment as 'concept architects' for the renovation of a Grade II listed building in the UK. The project allowed us to observe the dialogue between different actors who represented different modes of practice and embodied different values, disclosed through their explicit and implicit commentaries about the processes of building production. The project thus offered an opportunity to dramatize these encounters as value-conflicts in the building industry, relocated to Practiceopolis and contested in the spaces and cultures of that imaginary city (Figure 2).

The graphic novel drew from the value-conflicts that occurred during the project's Progress and Value Engineering Meetings. These meetings highlighted the presence of different cultures of practice represented by: our research-led office as concept architects; a 
Fig. 3 (below), Excerpts from the graphic novel "Stories from Practiceopolis" (the Authors). The novel argues that these value-conflicts are not confined specifically to the project involved but may also reflect the broader ethos of the contemporary building industry. facility management service, a technical-rational organization acting as the client's architectural representative; engineering consultants; contractors; quantity surveyors; and a multinational project manager. These participants' values played out around attitudes to efficient, profitable and timely delivery - usually seen as preferable by the actors whose values might broadly be characterized as technical-rational. The discussions made us acutely conscious not just of the values of our research-led practice but of certain priorities of architectural discourse, and the legacies of our architectural training. In the dramatized version of these meetings, these actors - and the various cultures of practice they represent - are working to articulate competing, high-stakes visions for the future of Practiceopolis. Combining ethnography and participant observation with 'by design' and cartooning methodologies, these stories indicate the range of preconceptions expressed by the different actors as value-conflicts not confined specifically to one project but the future of the broader ethos of the contemporary building industry (Figure 3).

The graphic novel is inspired by Jimenez Lai's architectural graphic novel Citizen of No Place (2012). ${ }^{3}$ The novel also takes inspiration from the Danish Architect Bjarke Ingels's Yes is More: An Archicomic on Architectural Evolution (2010). It adopts some of the techniques of storytelling he used to document and demonstrate the works of BIG, their methods and processes by means of cartoon. ${ }^{4}$ The novel builds on the work of Dana Cuff, Robert Gutman and Paolo Tombesi on the nature of the architectural profession and its challenges in the building industry and within the global capitalist market. ${ }^{5}$ In addition, it touches on the work of Jeremy Till concerning the need for architects to selfcritique their claims of autonomy and to understand the nature of our field. ${ }^{6}$




The novel consists of five sections. These sections feature descriptions of the ideological positions of the characters involved in the project, the history of the building located at the center of the debates, the proposed design intervention, the Progress Meetings recast as political debates, and ends with a deliberation on value conflicts in the profession set in Practiceopolis Parliament. The Progress Meetings section features different stories that revolve around design and technical issues which occurred during the project's development; each portraying the coexistence of different values at work in its execution.

One story, for example, 'the Warranty', depicted an instance where our office suggested using rolled-lead - a material already found in the existing fabric of building - to clad an existing, but not-original, addition. This was met with resistance from the project's technicalrational consultants. Both the University's facility management service and the main building contractor preferred a Sarnafil single ply membrane based on its ease of application, less health and safety issues over the handling of heavy materials and the system's 25 year paper warranty. They believed this system would offer a similar appearance to lead while being simpler to construct. We disagreed with these assumptions, preferring lead in this historic context as a more visually rich material with long cultural associations, a history of fine craftsmanship, durability and a patina that ages nicely. Lead, we argued, would be a complementary material in this context, detailed in a contemporary way. While it came with no paper warranty, long experience has shown lead to be a highly durable material requiring minimal maintenance, and its life-cycle cost appears reasonable when considered against the alternative single ply membrane (Figures $4-6$ ). 


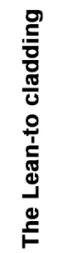


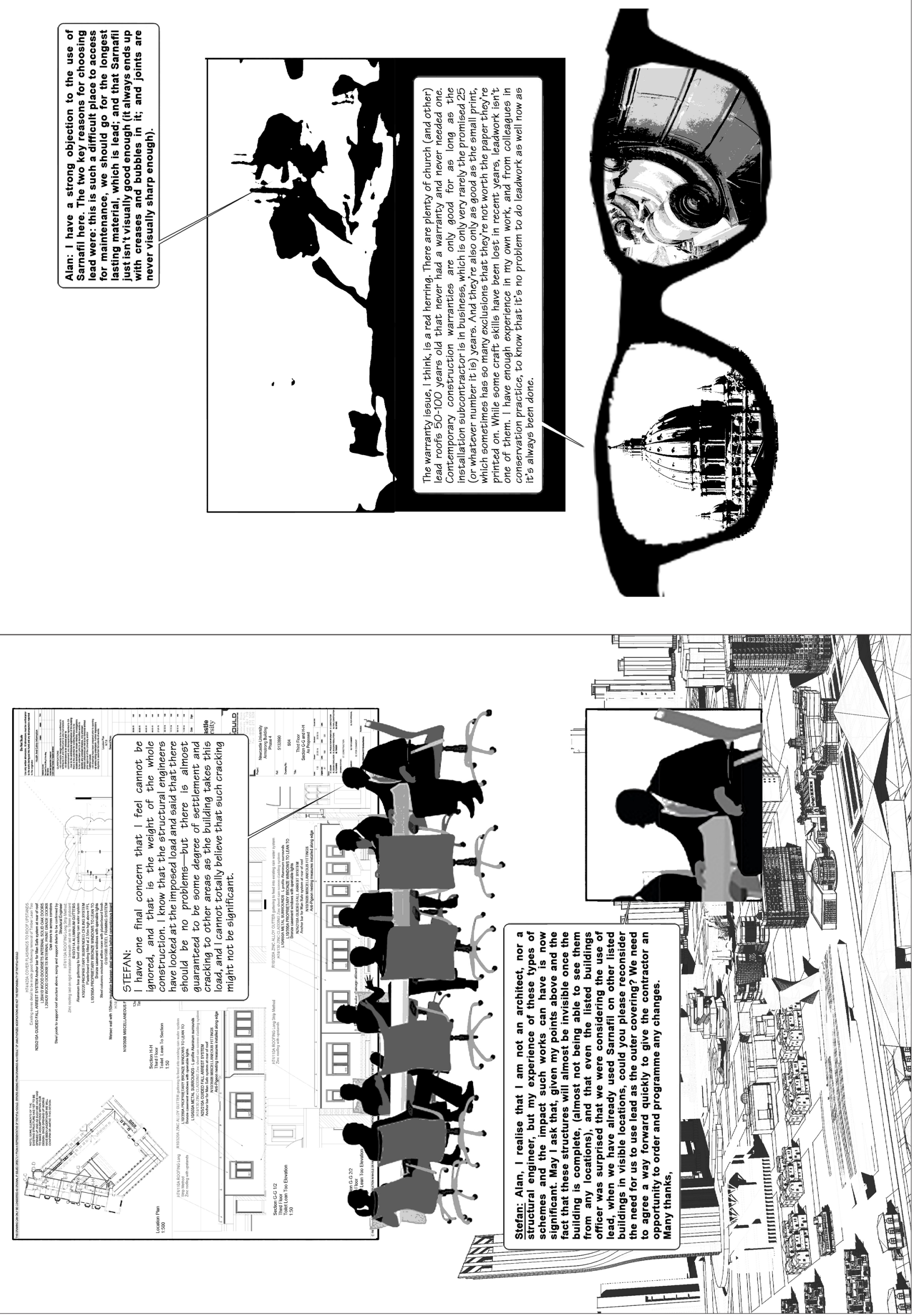


While it may seem almost trivial in the everyday world outside the novel, this issue in the project's design development nevertheless illustrated a difference of values and priorities between our office, as architects, and other actors in the industry. It was clear that the priority of the technical-rational actors were confined to ease of maintenance and the tick-boxes of health and safety regulation, whereas our values as architects were guided more by architectural ideas about new work expressing the values of its time in relation to historic fabric, the appropriateness of materials and detailing, long term value, and the celebration of craft. This story, among various others in the novel, invokes what Donald Schön would call 'reflective practice', involving the analysis of experience, paying critical attention to practical values and theories that inform everyday actions. ${ }^{7}$ They allow the examination of practice, reflectively and reflexively, in order to pursue wider lessons from them for the self-definition of the architectural profession.

The concluding part of the novel takes the various value conflicts happened in the project to Practiceopolis Parliament as a political debate around the future of Practiceopolis within the Confederation of the Building Industry. It accentuates and polarizes the debates to draw out the underlying themes they represent. In the tradition of dystopian worlds common in a certain strand of graphic novels, it ends pessimistically with a near future speculation, extrapolating present contemporary conditions to illustrate the end of the architectural profession, or its transformation into to a new profession, as a subsection of one of the technical-rational members of the industry (Figure 7-12). 

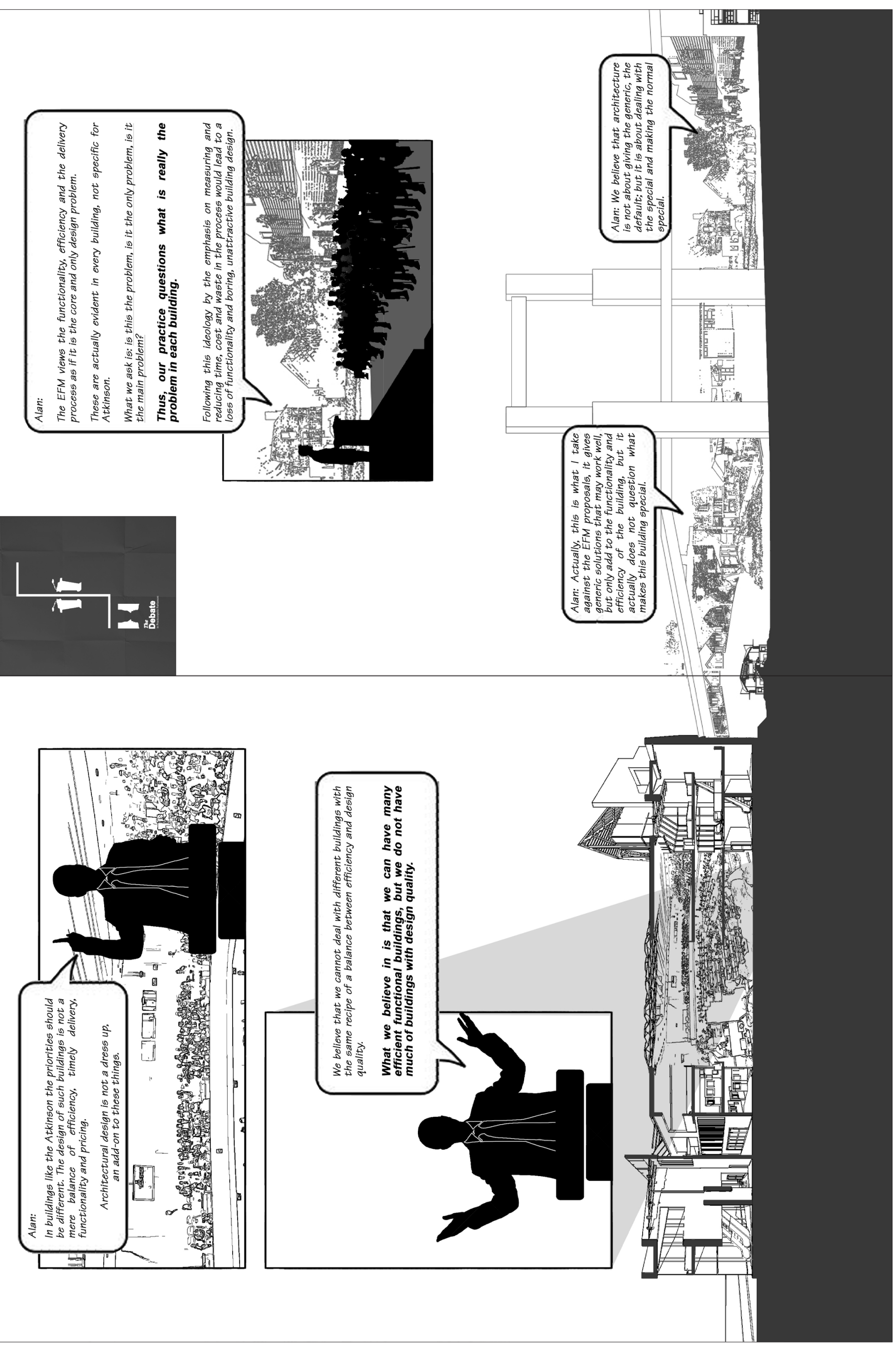


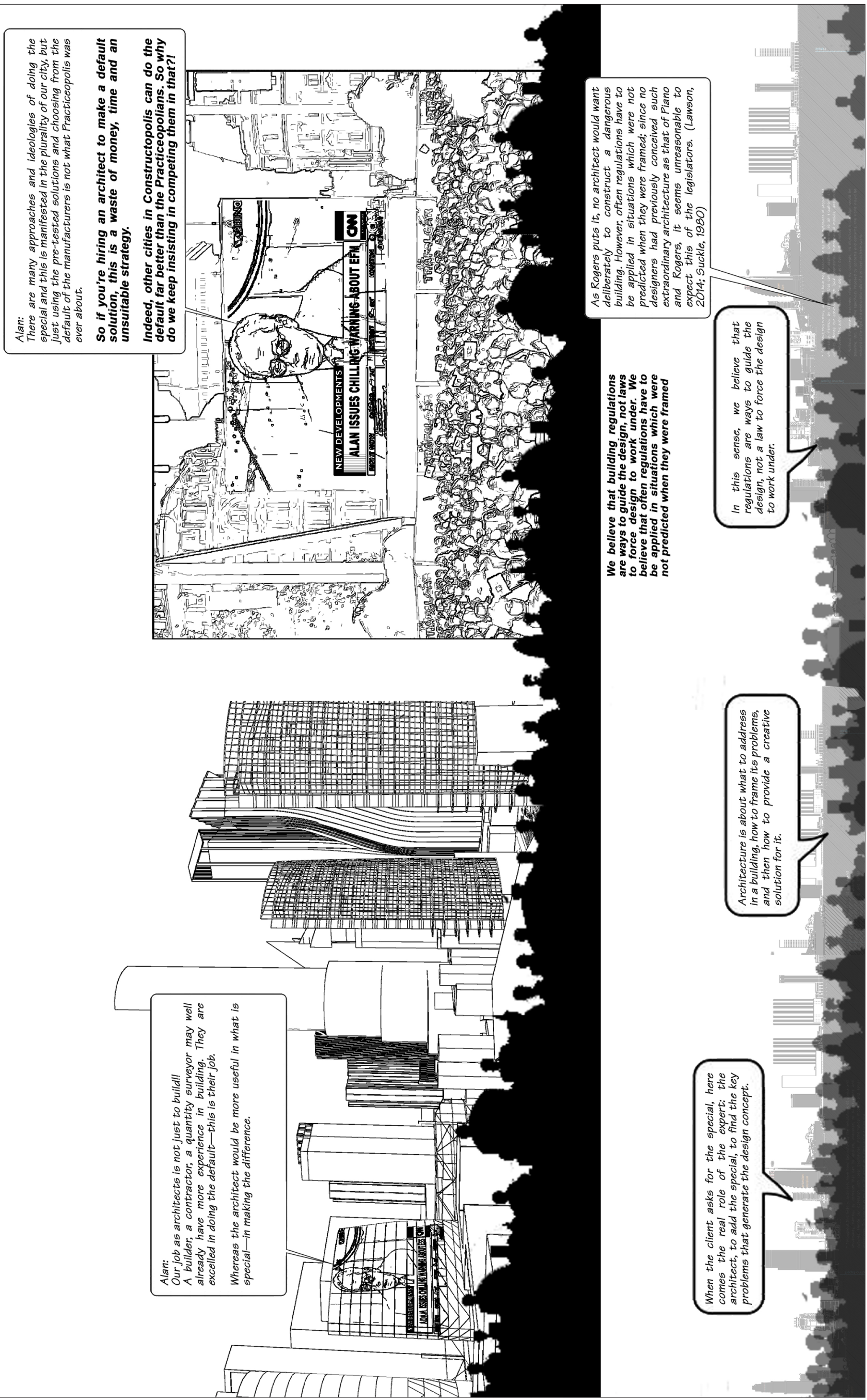



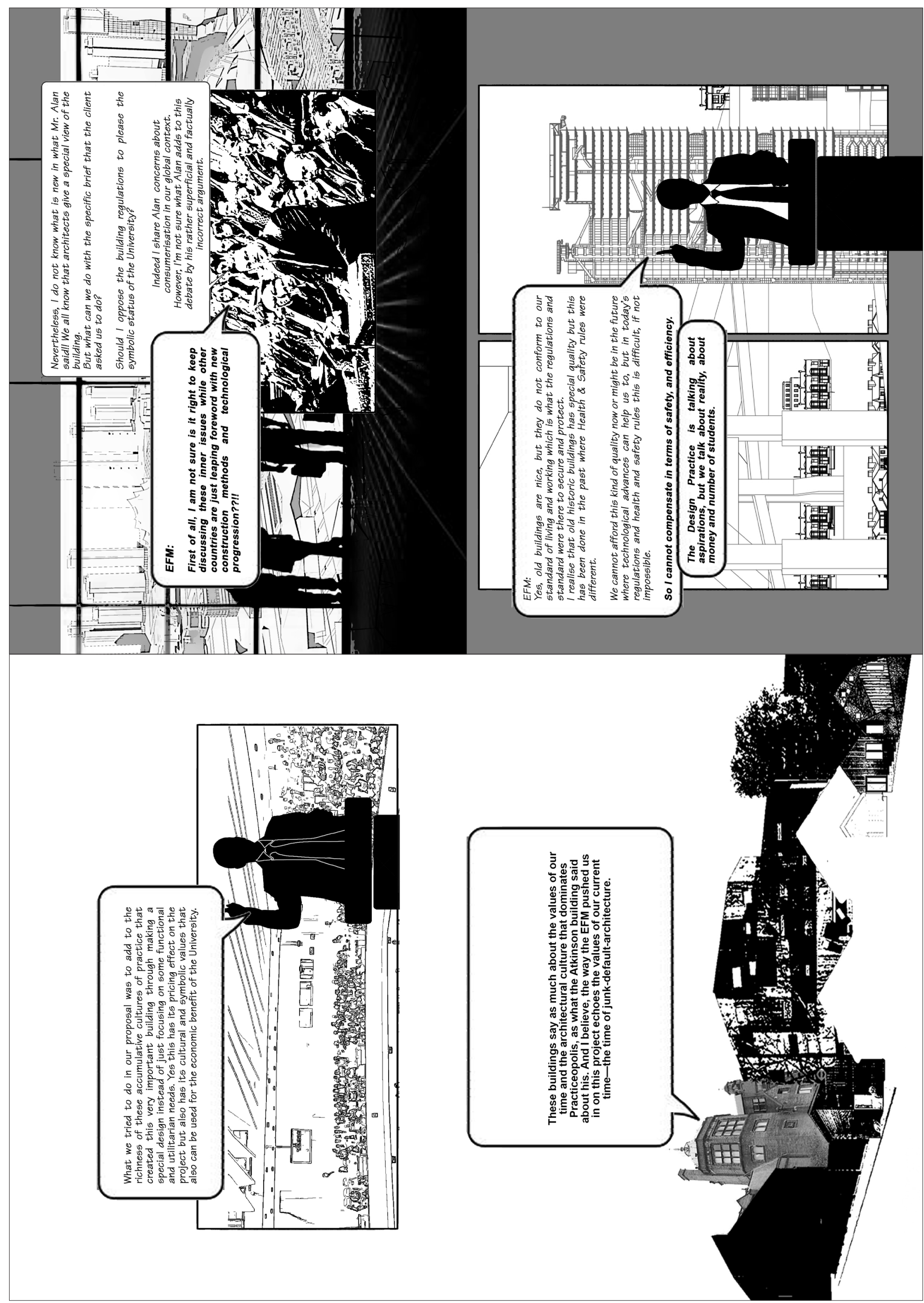

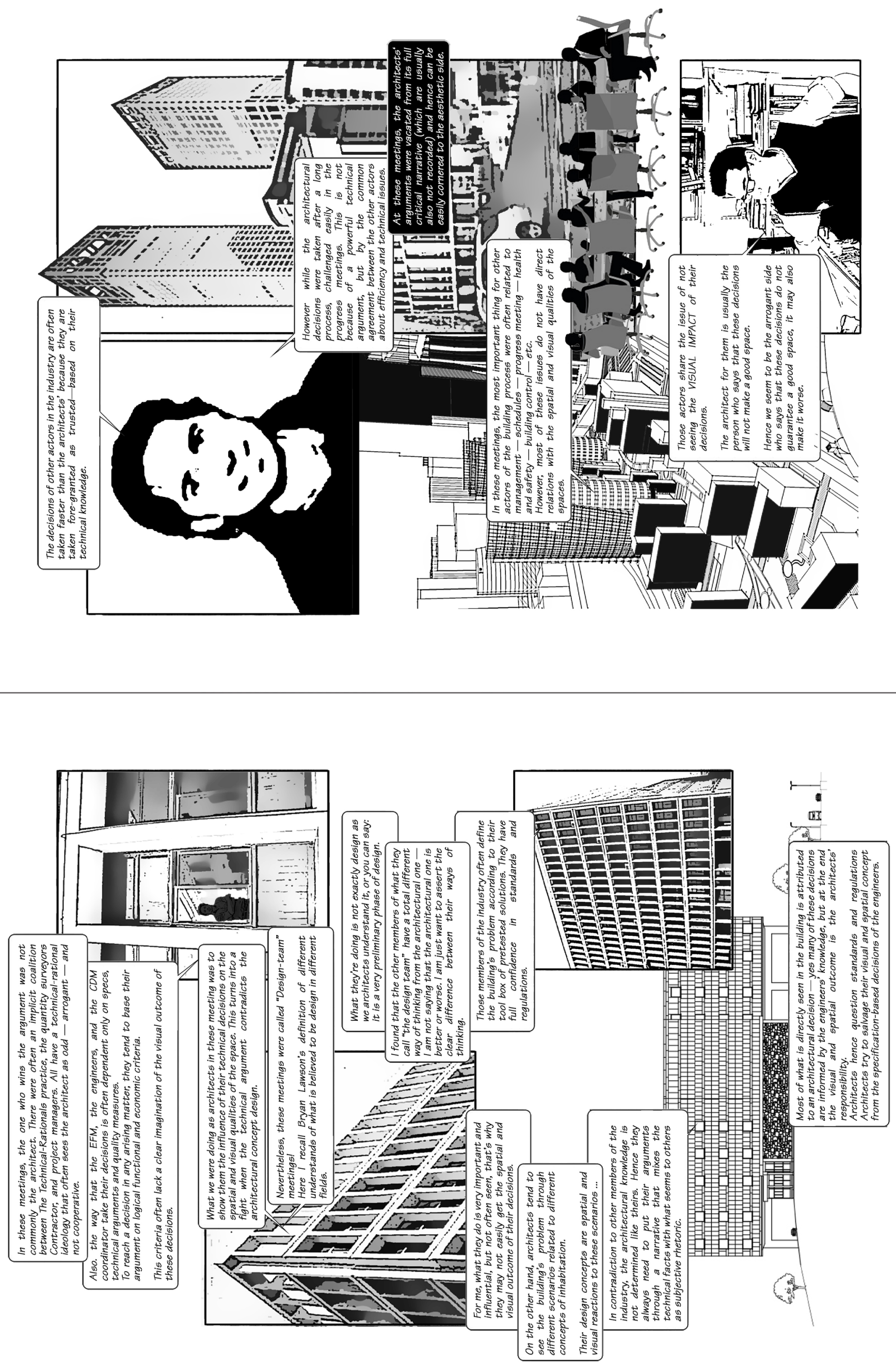









\section{CONCLUSION}

The metaphor of Practiceopolis began as a reading of the landscape of the contemporary architectural profession and as a parody of the notion of the ideal city. The graphic novel became a provocation, a tool for opening-up speculations about possible futures for architecture as a profession. As a blend of ethnographic observation with design and fiction, it represents a special creative space combining traditions of writing and storytelling with the crafting of cartoon drawings, explored through - and exploring - architectural creative processes. The novel is critical and satirical, using humor and parody to highlight the contradictions and misunderstandings that emerge when the somewhat incompatible worldviews of diverse actors involved in building production collide. It reflects on certain priorities of architectural discourse, and the legacies of architectural training within the complex conditions of the globalized building industry. The genre of the graphic novel permits values to be caricatured in a more extreme way and allows the claiming of a temporary authority to interrogate arguments from different intellectual positions. It communicates its argument through the accessible format of cartoons to provoke important questions about everyday and mundane routines of the architectural profession, reflecting on the largely tacit assumptions that inform contemporary building production. 
Fig. 12 The novel pessimistically ends with a near future speculation, extrapolating from present contemporary conditions conveyed in the novel. It shows the end of the architectural profession, or its change to a new profession, as a subsection of one of the technicalrational members of the industry.

\section{NOTES}

1 What is referred to here as 'technical-rational ideology' reflects the peak of applying analytic thinking, management theory, and systems thinking to building construction processes. This ideology tends to understand the construction process through notions of practicality, productivity, and timely delivery, represented often in tangible quantitative metrics of quality control. It involves following strict codes, regulations, and coordination protocols as well as satisfying the pressing economic requirements of the increasingly complex conditions of the globalized world.

2 Feenberg, A. Questioning Technology (New York: Routledge, 2012).

3 Lai, J., Citizens of No Place: An Architectural Graphic Novel (New York: Princeton Architectural Press, 2012).

4 Ingels, B., Ginsberg, E., Pahhota, D., Zahle, D., Johansson, H., Pedersen, A. and Bergman, K.U., Yes is more: An Archicomic on Architectural Evolution (Koln: Taschen, 2010).

5 Cuff, D., Architecture: The Story of Practice (Massachusetts: MIT Press, 1992). Cuff, D., "The Political Paradoxes of Practice: Political Economy of Local and Global Architecture", arq: Architectural Research Quarterly, 3(1),(1999): pp. 77-88.

Gutman, R. Architectural Practice: ACritical View (New York: Princeton Architectural Press, 1996).

Tombesi, P., "Architectural Feasts or Professional Fausts? A double perspective on the bargains of globalization" [Series of two parts]: Part 2', Architecture Australia, (2004): 93(4).

6 Till, J., Architecture Depends. (Cambridge, Massachusetts: MIT Press, 2013)

7 Schön, D.A., The Reflective Practitioner: How Professionals Think in Action (London: Routledge, 2017) 